\title{
Article \\ A Comparative Assessment of the Chronic Effects of Micro- and Nano-Plastics on the Physiology of the Mediterranean Mussel Mytilus galloprovincialis
}

\author{
Marco Capolupo *, Paola Valbonesi and Elena Fabbri
}

Citation: Capolupo, M.; Valbonesi,

P.; Fabbri, E. A Comparative

Assessment of the Chronic Effects of

Micro- and Nano-Plastics on the Physiology of the Mediterranean Mussel Mytilus galloprovincialis.

Nanomaterials 2021, 11, 649. https:// doi.org/10.3390/nano11030649

Academic Editor: Joachim Clement

Received: 13 February 2021

Accepted: 2 March 2021

Published: 7 March 2021

Publisher's Note: MDPI stays neutral with regard to jurisdictional claims in published maps and institutional affiliations.

Copyright: (c) 2021 by the authors. Licensee MDPI, Basel, Switzerland. This article is an open access article distributed under the terms and conditions of the Creative Commons Attribution (CC BY) license (https:/ / creativecommons.org/licenses/by/ $4.0 /)$.
Department of Biological, Geological, and Environmental Sciences, University of Bologna, Via Sant' Alberto 163, 48123 Ravenna, Italy; paola.valbonesi@unibo.it (P.V.); elena.fabbri@unibo.it (E.F.)

* Correspondence: marco.capolupo2@unibo.it

\begin{abstract}
The ocean contamination caused by micro- and nano-sized plastics is a matter of increasing concern regarding their potential effects on marine organisms. This study compared the effects of a 21-day exposure to 1.5, 15, and $150 \mathrm{ng} / \mathrm{L}$ of polystyrene microplastics (PS-MP, 3- $\mu \mathrm{m}$ ) and nanoplastics (PS-NP, 50-nm) on a suite of biomarkers measured in the Mediterranean mussel Mytilus galloprovincialis. Endpoints encompassed immunological/lysosomal responses, oxidative stress/detoxification parameters, and neurotoxicological markers. Compared to PS-MP, PS-NP induced higher effects on lysosomal parameters of general stress. Exposures to both particle sizes increased lipid peroxidation and catalase activity in gills; PS-NP elicited greater effects on the phase-II metabolism enzyme glutathione S-transferase and on lysozyme activity, while only PS-MP inhibited the hemocyte phagocytosis, suggesting a major role of PS particle size in modulating immunological/detoxification pathways. A decreased acetylcholinesterase activity was induced by PS-NP, indicating their potential to impair neurological functions in mussels. Biomarker data integration in the Mussel Expert System identified an overall greater health status alteration in mussels exposed to PS-NP compared to PS-MP. This study shows that increasing concentrations of nanoplastics may induce higher effects than microplastics on the mussel's lysosomal, metabolic, and neurological functions, eventually resulting in a greater impact on their overall fitness.
\end{abstract}

Keywords: polystyrene; nano-fragmentation; marine bivalves; biomarkers

\section{Introduction}

Plastic is the most prevalently used material in modern society; it supports nearly all socio-economic activities, including household, health, and food sectors, and its production has exponentially soared in the past 70 years, reaching 368 million tons in 2019 [1]. Around $40 \%$ of daily used plastics are represented by single-use items, such as bags, bottles, and/or packages, which can easily be subjected to improper use or disposal. The management of plastic waste has consequently emerged as a major environmental issue in the latest decades [2]. According to Pinto da Costa et al. [3], 79\% of plastics sent to landfills finally find their way to oceans, for an estimated annual amount of 4.8-12.7 million tons. Plastic polymers do not tend to degrade in marine systems; rather, they experience a swift additive loss with consequent fragmentation into smaller pieces from the effect of weathering forces $[2,4,5]$. As a result, $94 \%$ of plastics currently present in oceans are represented by $<5 \mathrm{~mm}$ fragments [3], conventionally referred to as microplastics (MP) [6].

Many recent investigations focused on the interaction between $\mathrm{MP}$ and the marine biota. Because of their small size, variable shape/color, and seawater-alike density, MP frequently ends up being accidentally ingested (directly or via biomagnification) by marine organisms from different trophic levels, causing adverse biological effects at different scales of observation $[7,8]$. The main documented alterations include gut occlusion and reduced feeding stimulus (associated with reduced growth/fertility) in turtles and seabirds [9,10], 
metabolic and reproductive disorders in fish [11,12], and behavioral/nutritional alterations in invertebrates, like arthropods, annelids, and mollusks [13-15]. Besides, recent studies on bivalves report the alterations of cellular, biochemical and ontogenetic pathways, accenting the risks posed by MP on the processes governing the physiological adaptation to external stressors and population recruitment patterns [16-18].

A recent paradigm in marine plastic pollution is that the progressive plastic fragmentation to the nanoscale will expose organisms to far more subtle effects than observed for micro-scaled fragments [4]. Plastics of a size $<100 \mathrm{~nm}$, conventionally termed nanoplastics (NP) [19], may easily cross biological membranes, entering cells/tissue [20]; in addition, they display a relatively high surface to volume ratio, which may increase their reactivity toward organic compounds of endogenous or exogenous nature [4]. From a toxicological viewpoint, these features would enhance the NP's potential to interfere with molecular, cellular, and/or physiological mechanisms, likely impacting higher biological functions in the long term. Exposure to NP was recently found to induce Reactive Oxygen Species (ROS) overproduction in the marine bacterium Halomonas alkaliphila [21], transcriptomic changes in the brine shrimp Artemia franciscana [22], and alterations of several biochemical/cellular pathways in mussels of the Mytilus spp., including lysosomal/biotransformation processes, ROS-scavenging mechanisms, immune response and gene expression [23-25]. Most of these studies focused on the acute or sub-chronic impact of virgin and/or conditioned (e.g., aminated or carboxilated) NP alone; on the other hand, little is still known about the differences between the effects of micro- and nano-sized plastics on the physiology of marine organisms, notably following prolonged exposures.

The aim of the present study is to comparatively assess the chronic effects of 3- $\mu \mathrm{m}$ polystyrene MP (PS-MP) and 50-nm polystyrene NP (PS-NP) on a suite of physiological, cellular, and biochemical parameters measured in the Mediterranean mussel Mytilus galloprovincialis. This species has been chosen based on its ease of collection/rearing, wide geographical distribution, filter-feeding habits, and well-known responsiveness to stress conditions [26]. A battery of biomarkers of environmental stress were measured following 21 days of mussel exposure to increasing concentrations of PS-MP and PS-NP.

\section{Materials and Methods}

\subsection{Experimental Design}

Sexually mature specimens of the Mediterranean mussel Mytilus galloprovincialis (4-6 cm length) were collected in a high-quality marine area (Cesenatico, NW-Adriatic Sea) and immediately transferred to laboratory, where they were acclimated for 5 days at $16^{\circ} \mathrm{C}$ and 10:14 $\mathrm{h}$ (light:dark) photoperiod. Afterward, animals were divided into groups of 20 individuals and separately exposed for 21 days to 1.5, 15, and $150 \mathrm{ng} / \mathrm{L}$ of 3- $\mu \mathrm{m}$ PS-MP and 50-nm PS-NP (described in detail in SM, section S1) into tanks containing $20 \mathrm{~L}$ of filtered seawater (FSW), each representing the experimental replicates $(\mathrm{N}=3)$. Treatments were selected with the aim to estimate the sub-lethal impact associated with the fragmentation of a fixed amount of plastics from the micro to the nanoscale, as is expected to occur in natural environments due to effects of weathering processes [4]. In terms of nominal concentration of particles/volume unit, chosen treatments corresponded to 100, 1000, and 10,000 PS-MP/L and $2.17 \times 10^{5}, 2.17 \times 10^{6}$, and $2.17 \times 10^{7} \mathrm{PS}-\mathrm{NP} / \mathrm{L}$. PS-MP and PS-NP concentrations were renewed daily after a water change. A control (CTR) treatment containing no particles was performed in parallel. After collection, mussel tissues were immediately analyzed for selected endpoints (hemolymph) or stored at $-80{ }^{\circ} \mathrm{C}$ for subsequent analyses (gills, digestive gland). To debate the likelihood of biases due to inter-individual variability, data from each replicate (vessel) consisted of the mean ( \pm Standard Error of Mean, SEM) level of selected endpoints from 4 randomly selected mussels per replicate (12 mussels per experimental condition). For biomarkers analyzed spectrophotometrically, data were normalized on the total protein content according to Lowry et al. [27]. 


\subsection{Lysosomal Parameters}

\subsubsection{Lysosomal Membrane Stability (LMS)}

The effect of PS-MP and PS-NP on the lysosomal membrane stability (LMS) of mussel hemocytes was evaluated using the Neutral Red Retention Assay (NRRA) as described by Martinez-Gomez et al. [28]. The method is based on exposing hemocytes to a solution containing $0.01 \%$ Neutral Red (NR, Sigma-Aldrich ${ }^{\circledR}$, Milan, Italy) acidophile dye (which migrates into lysosomes) and on the assessment of the Neutral Red Retention Time (NRRT), which is the time ( $\mathrm{min}$ ) where more than $50 \%$ of the lysosomes released the dye into the cytosol.

\subsubsection{Histopathological Alterations}

The lysosome to cytoplasm volume ratio (LYS/CYT) and the intra-lysosomal content of lipofuscin (LF) and unsaturated neutral lipids (NL) were assessed in histological cryo-sections of the mussel digestive gland obtained according to the UNEP/RAMOGE guidelines [29]. Glands of four mussels per tank were dissected, placed on aluminum supports for cryotomy (chuck), and rapidly frozen in N-hexane before being stored at $-80^{\circ} \mathrm{C}$. Ten- $\mu \mathrm{m}$ gland sections were obtained using a cryotome at $-30{ }^{\circ} \mathrm{C}$, rapidly placed onto glass slides, and selectively stained for chosen parameters, as described below.

The LYS/CYT was performed according to Capolupo et al. [30] by selectively staining the reaction between the lysosomal hydrolase $\mathrm{N}$-acetyl- $\beta$-hexosaminidase and a specific substrate. Briefly, sections were shaken for $20 \mathrm{~min}$ at $37^{\circ} \mathrm{C}$ in the presence of the substrate naphtol AS-BI N-acetyl- $\beta$-D-glucosaminide (Sigma-Aldrich ${ }^{\circledR}$, Milan, Italy) and stained using the diazonium dye "Fast Violet B" $(1 \mathrm{mg} / \mathrm{mL}$ in $0.1 \mathrm{M}$ phosphate buffer, $\mathrm{pH}$ 7.4) (Sigma-Aldrich ${ }^{\circledR}$, Milan, Italy). The NL and LF content were assessed according to MartinDiaz et al. [31]. For NL, sections were fixed in formol calcium for $15 \mathrm{~min}$ at $4{ }^{\circ} \mathrm{C}$, transferred into $60 \%$ triethylphosphate (Carlo Erba ${ }^{\circledR}$, Milan, Italy) for $3 \mathrm{~min}$. and stained in a $1 \%$ oil red O (Sigma-Aldrich ${ }^{\circledR}$, Milan, Italy) staining solution for $15 \mathrm{~min}$ in the dark. For LF, slides were fixed as for NL and selectively dyed for $5 \mathrm{~min}$. in the dark using the Schmorl solution ( $1 \%$ ferric chloride and $1 \%$ potassium ferricyanide at a 3:1 ratio).

The three parameters were assessed at $40 \times$ magnification under a light microscope (Axioskop 40, Carl Zeiss, Milan, Italy) equipped with a digital camera (AxioCam MRc, Carl Zeiss, Milan, Italy). Four photos per gland were taken randomly and analyzed using the software Scion Image ver. 4.0.2.

\subsection{Biochemical and Enzymatic Biomarkers}

The content of malondialdehyde (MDA) and the activities of the enzymes glutathione S-transferase (GST), catalase (CAT), and acetylcholinesterase (AChE), were assessed spectrophotometrically in samples of mussel digestive gland and/or gills preliminarily processed at the specific conditions reported in SM (Table S1). The MDA content was quantified in digestive glands according to Franzellitti et al. [32] by interpolating the data of absorbance at $570 \mathrm{~nm}$ on a standard curve obtained using the MDA precursor 1,1,3,3Tetramethoxypropan (TMOP, Sigma-Aldrich ${ }^{\circledR}$, Milan, Italy). GST and CAT activities were measured in both digestive glands and gills according to Capolupo et al. [33]. GST activity was evaluated at $340 \mathrm{~nm}$ by following the reaction kinetics between the enzyme and the substrate 1-chloro-2,4-dinitrobenzene (CDNB, Sigma-Aldrich ${ }^{\circledR}$, Milan, Italy) for $10 \mathrm{~min}$ (at 1 min intervals). Similarly, CAT activity was measured by tracking the decrease in the absorbance of samples at $240 \mathrm{~nm}$ for $2 \mathrm{~min}$ (at $10 \mathrm{~s}$ intervals) in the presence of $55 \mathrm{mM}$ $\mathrm{H}_{2} \mathrm{O}_{2}$. AChE activity was determined in gills at $405 \mathrm{~nm}$ as described by Valbonesi et al. [34]. Samples were read at $405 \mathrm{~nm}$ for $10 \mathrm{~min}$ in the presence of $0.5 \mathrm{mM}$ acetylthiocholine iodide and 0.33 mM 5.5'-dithiobis-2-nitrobenzoic acid (DTNB, Sigma-Aldrich ${ }^{\circledR}$, Milan, Italy). 


\subsection{Immunological Parameters}

\subsubsection{Lysozyme Enzymatic Assay}

The lysozyme-specific activity was assessed in the mussel hemolymph serum according to the protocol described by Chu and La Peyre [35]. The method is based on the decrease of absorbance of the hemolymph serum proportionally to the lytic action of lysozyme toward the bacterium Micrococcus lysodeikticus (Sigma-Aldrich ${ }^{\circledR}$, Milan, Italy). Firstly, $500 \mu \mathrm{L}$ hemolymph was centrifuged at $4{ }^{\circ} \mathrm{C}$ for $10 \mathrm{~min}$ at $400 \times g$ to separate serum and hemocytes; hence, the supernatant (serum) was rapidly added to a solution containing $0.9 \mathrm{mg} / \mathrm{mL}$ of $M$. lysodeikticus cells in $0.066 \mathrm{M}$ phosphate buffer $\left(\mathrm{pH} 6.24\right.$ at $25^{\circ} \mathrm{C}$ ) and read spectrophotometrically at $450 \mathrm{~nm}$ at $1 \mathrm{~min}$ intervals for $10 \mathrm{~min}$ total. The lysozyme activity was expressed as milliunits $(\mathrm{mU}) / \mathrm{mg}$ of total proteins, $1 \mathrm{U}$ being the activity resulting in a decrease of $0.001 \mathrm{OD} / \mathrm{mL}$ sample.

\subsubsection{Phagocytosis}

The phagocytic activity of mussel hemocytes has been assessed according to Canesi et al. [36]. Aliquots $(20 \mu \mathrm{L})$ of hemolymph were placed and kept on microscope slides for $30 \mathrm{~min}$ at $16{ }^{\circ} \mathrm{C}$ in a dark and wet room to allow for hemocyte adhesion. Cells were exposed to a $0.05 \%$ solution of zymosan yeast (Saccharomyces cerevisiae, Sigma-Aldrich ${ }^{\circledR}$, Milan, Italy) particles (Sigma, Z4250), preliminarily stained with Neutral Red in $0.05 \mathrm{M}$ Tris- $\mathrm{HCl}(2.5 \% \mathrm{NaCl}, \mathrm{pH}$ 7.6). After $1 \mathrm{~h}$, hemocytes were fixed by adding Baker's formol solution to each slide. The phagocytic efficiency was evaluated under a light microscope (Zeiss Axioskop 40, 40× magnification) and expressed as a percentage of hemocytes showing zymosan particles phagocytosis.

\subsection{Statistical Analysis and Data Integration}

Significant differences between treated and control mussels, as well as between PSMP and PS-NP-treated mussels, were determined using the SIGMAPLOT 13 statistical package (Systat Software Inc. San Jose, CA, USA). After verifying the deviations from parametric Analysis of Variance (ANOVA) (normality: Shapiro-Wilk test; equal variance: Brown-Forsythe test), data were analyzed using a non-parametric Kruskal-Wallis followed by the Mann-Whitney (Rank Sum) U-test for multiple comparisons. In any case, the statistical difference was accepted when $p<0.05$. A principal component analysis (PCA) was performed on data from single factors using the software PRIMER v6 (PRIMER-E Ltd., Albany, New Zealand) to ascertain the amount of variation explained by singles treatments/endpoints and allow for a comparable interpretation of the obtained results.

Biomarker data were integrated using the Mussel Expert System (MES) developed by Dagnino et al. [37] to define a synoptic health status index (HSI) for each tested condition. Data showing significant alterations were processed to obtain an alteration factor (AF), which is the ratio between the means of that specific value and control. An alteration level (AL) was generated by comparing any AFs with a specific threshold defined based on the toxicological profile expressed by each biomarker (i.e., increasing, decreasing, or bell-shaped response) and the hierarchical level at which alterations occur (cell, tissue, organism). Finally, the system applies a multiple-step algorithm to evaluate and define the A-E scaled HSI ranging from A (healthy) to E (pathological status) for each of the performed treatments. The most sensitive biomarker of the list was selected as a guide parameter (GP) and changes in its AL values were primarily considered by the system to interpret the overall mussel health status.

\section{Results}

A wide set of biological endpoints were measured in mussels exposed for 21 days to 1.5, 15, and $150 \mathrm{ng} / \mathrm{L}$ of PS-MP and PS-NP, including lysosomal biomarker of general stress (LMS, NL, and LYS/CYT), lipid peroxidation parameters (LF and MDA), antioxidant/detoxification enzymes (GST and CAT activities), neurological (AChE activity) and immunological parameters (lysozyme activity and phagocythosis). Finally, biological ef- 
fects induced by the two particle types were integrated using the Mussel Expert System to identify the overall impact induced by their administration on the mussel health status.

\subsection{Effects of PS-MP and PS-NP on Lysosomal Parameters of General Stress}

The effects induced by PS-MP and PS-NP on selected lysosomal parameters are shown in Figure 1. With respect to control, both types of particles induced a significant LMS decrease in mussel hemocytes at all tested concentrations, except for $1.5 \mathrm{ng} / \mathrm{L}$ PS-MP (Figure 1A). In addition, NRRTs measured at 15 and $150 \mathrm{ng} / \mathrm{L}$ PS-NP showed significantly lower levels compared to those observed at the same PS-MP concentrations.
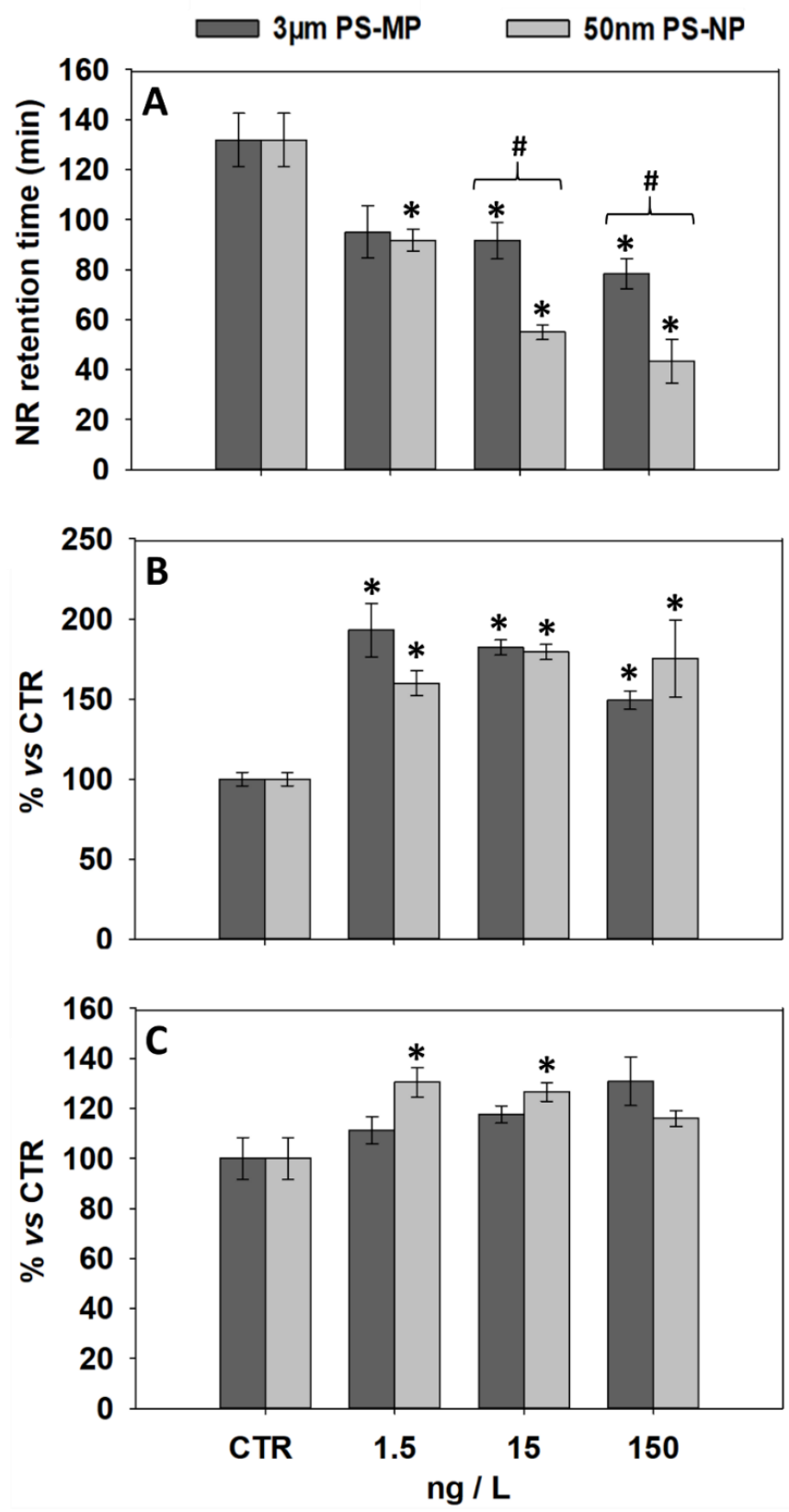

Figure 1. Lysosomal parameters (mean $\pm \mathrm{SEM}, \mathrm{N}=3$ ) analyzed in mussels after 21 days of exposure to polystyrene microplastics (PS-MP) and polystyrene nanoplastics (PS-NP); (A), Lysosomal Membrane Stability (LMS) assessed in mussel hemocytes; (B), lysosomal content of unsaturated neutral lipids (NL) in mussel digestive gland; (C), lysosome to cytoplasm volume ratio (LYS/CYT) in mussel digestive cells. *, significant $(p<0.05)$ differences compared to control samples (CTR); \#, significant differences $(p<0.05)$ between PS-MP and PS-NP treatments. 
NL levels in the mussel digestive gland showed a significant increase versus control after exposure to all tested concentrations of PS-MP and PS-NP (Figure 1B). LYS/CYT showed no significant change versus control in mussels exposed to all PS-MP treatments, while a significant increase was observed after exposure to 1.5 and $15 \mathrm{ng} / \mathrm{L}$ PS-NP (Figure 1C). NL and LYS-CYT levels did not statistically differ between mussels exposed to PS-MP and PS-NP treatments (Figure 1B,C).

\subsection{Effects of PS-MP and PS-NP on Levels of LF and MDA}

The levels of lipid peroxidation products LF and MDA assessed in the digestive gland of mussels exposed to PS-MP and PS-NP are shown in Figure 2. Compared to the control, LF significantly increased at 1.5 and $15 \mathrm{ng} / \mathrm{L}$ PS-MP and at $150 \mathrm{ng} / \mathrm{L}$ PS-NP (Figure 2A). Mussels exposed to 1.5 and $15 \mathrm{ng} / \mathrm{L}$ PS-NP showed significantly lower LF values than observed at the same concentrations of PS-MP. MDA content was up-regulated only by the exposure to $150 \mathrm{ng} / \mathrm{L}$ of both PS particle sizes (Figure 2B). Overall, MDA levels did not show significant differences between PS-NP and PS-MP treatments.
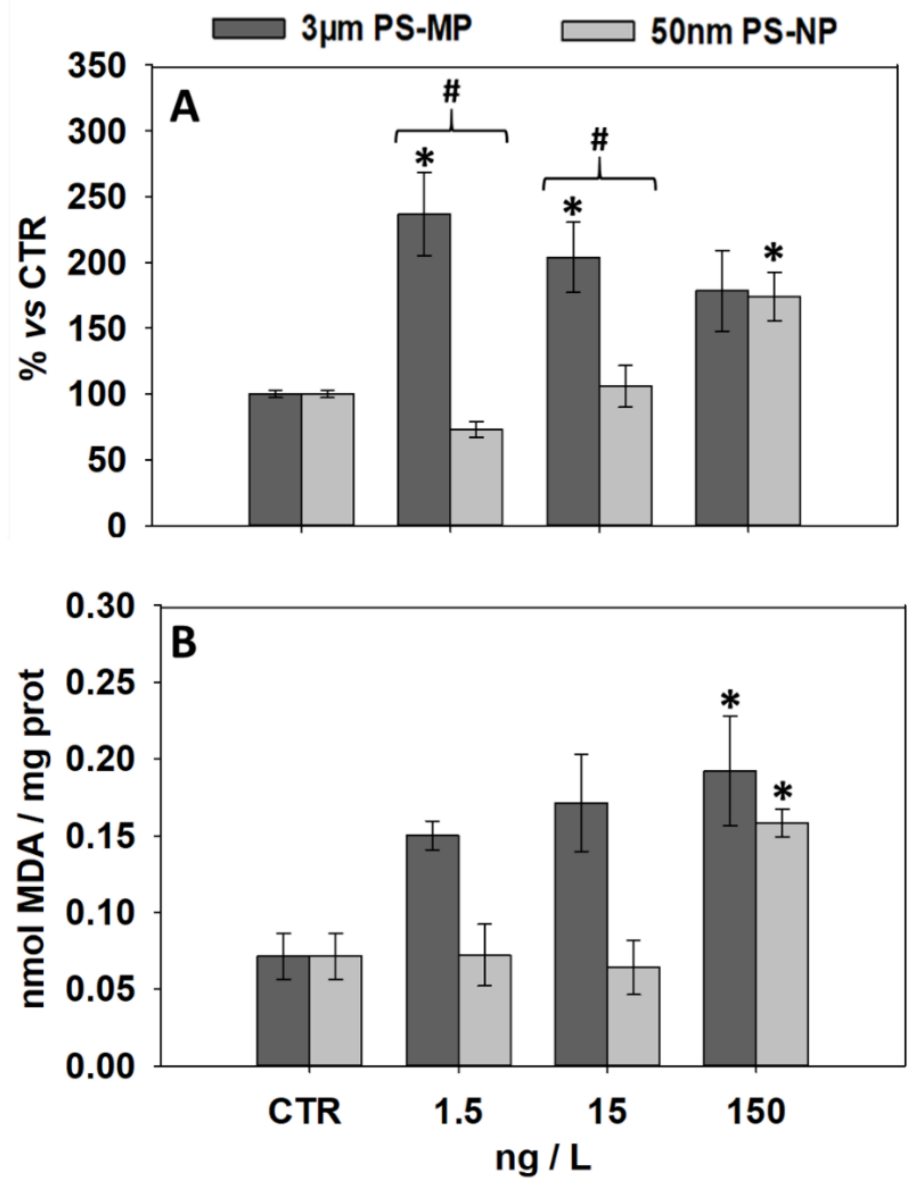

Figure 2. Lipid peroxidation parameters (mean $\pm \mathrm{SEM}, \mathrm{N}=3$ ) analyzed in mussels after 21 days of exposure to PS-MP and PS-NP; (A), intra-lysosomal content of lipofuscin (LF) content in the digestive gland; (B), malondialdehyde (MDA) content in the digestive gland. *, significant $(p<0.05)$ differences compared to control samples (CTR); \#, significant differences $(p<0.05)$ between PS-MP and PS-NP treatments.

\subsection{Effects of PS-MP and PS-NP on the Activities of GST and CAT}

The effects induced by PS-MP and PS-NP on the specific activity of the enzymes GST and CAT are displayed in Figure 3. In the digestive gland, no change in GST activity was observed compared to control after exposure to all treatments of both particle sizes (Figure 3A), while a significant increase was induced in gills of mussels exposed to 15 
and $150 \mathrm{ng} / \mathrm{L}$ PS-NP (Figure 3B). Similarly, CAT activity in the digestive gland showed no change versus control after exposure to all treatments, although levels measured at $150 \mathrm{ng} / \mathrm{L}$ PS-MP were significantly lower than those measured at the same concentration of PS-NP (Figure 3C). In gills, a significant CAT activity increase was induced by the exposure to $1.5 \mathrm{ng} / \mathrm{L}$ of both particle types and at $15 \mathrm{ng} / \mathrm{L}$ PS-MP, the latter showing significantly higher levels compared to the same concentration of PS-NP.
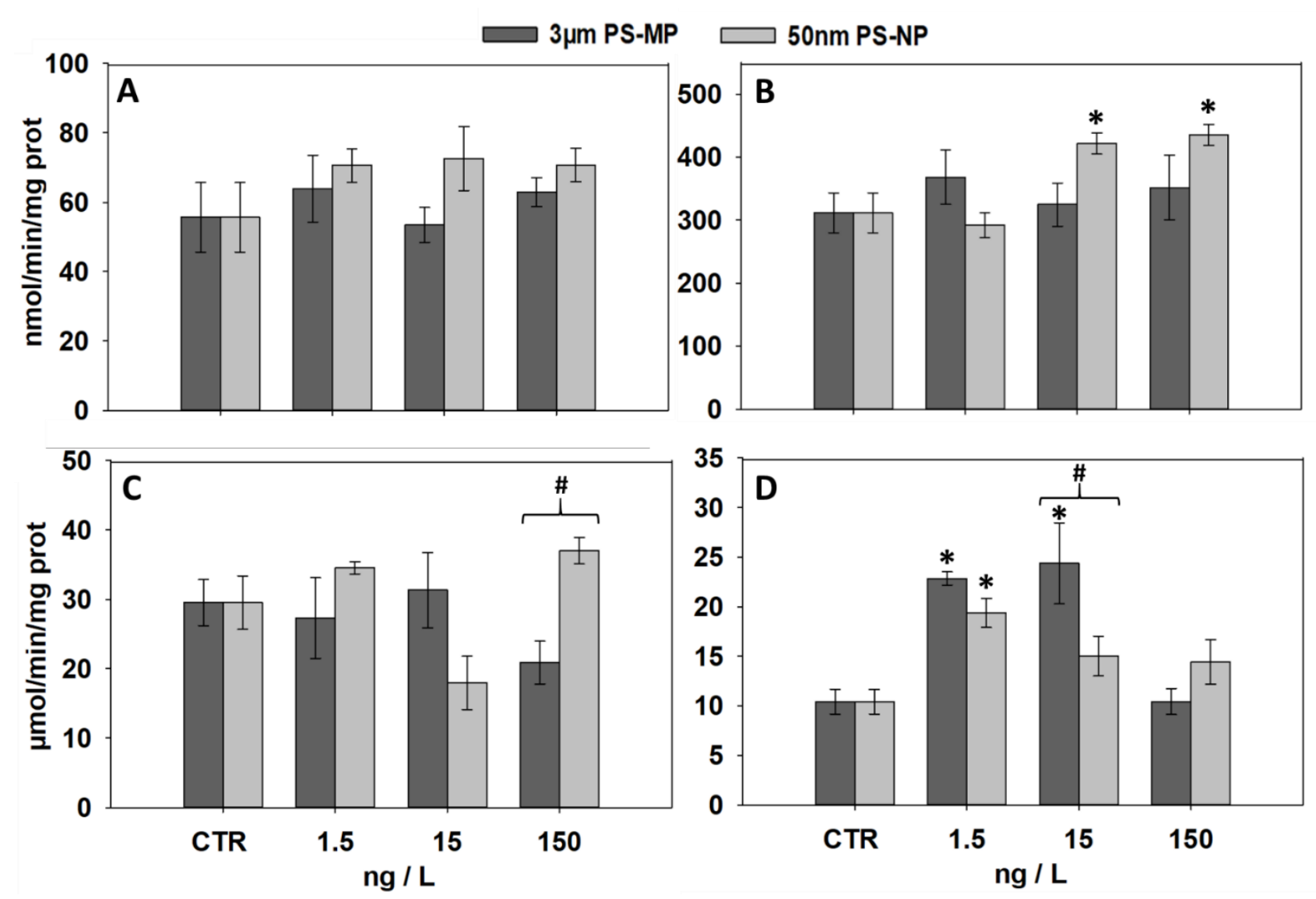

Figure 3. Activity of antioxidant/detoxification enzymes (mean $\pm \mathrm{SEM}, \mathrm{N}=3$ ) analyzed in mussels after 21 days of exposure to PS-MP and PS-NP; (A,B), glutathione S-transferase (GST) activity in mussel digestive gland (A) and gills (B); $(\mathbf{C}, \mathbf{D})$, catalase (CAT) activity in mussel digestive gland $(\mathbf{C})$ and gills $(\mathbf{D}) ;{ }^{*}$, significant $(p<0.05)$ differences compared to control samples (CTR); \#, significant differences $(p<0.05)$ between PS-MP and PS-NP treatments.

\subsection{Effects of PS-MP and PS-NP on Immunological and Neurological Parameters}

Figure 4 shows the effects induced by increasing PS-MP and PS-NP concentrations on the hemolymph serum lysozyme activity, the hemocyte phagocytosis, and the AChE activity in gills. Compared to controls, a significantly decreased lysozyme activity was observed after mussel exposure to 1.5 and $15 \mathrm{ng} / \mathrm{L}$ PS-MP, while PS-NP treatments resulted in a significant increase at $1.5 \mathrm{ng} / \mathrm{L}$ followed by a decrease at 15 and $150 \mathrm{ng} / \mathrm{L}$ (Figure 4A). Compared to PS-NP, levels of lysozyme activity measured in PS-MP-exposed mussels were significantly lower at $1.5 \mathrm{ng} / \mathrm{L}$ and significantly higher at $150 \mathrm{ng} / \mathrm{L}$ (Figure $4 \mathrm{~A}$ ).

The phagocytic activity of mussel hemocytes was significantly inhibited compared to the control after the exposure to 1.5 and $15 \mathrm{ng} / \mathrm{L}$ PS-MP (Figure 4B); conversely, no effect was observed at any PS-NP treatments and no difference was observed, at any treatment, between PS-MP and PS-NP treatments (Figure 4B). No effect was induced by any PS-MP treatments on the activity of AChE measured in mussel gills (Figure 4C); on the other hand, a significant AChE decrease was induced by PS-NP at $15 \mathrm{ng} / \mathrm{L}$. No significant change 
was noted between the AChE activity measured in PS-NP- and PS-MP-treated mussels (Figure 4C).
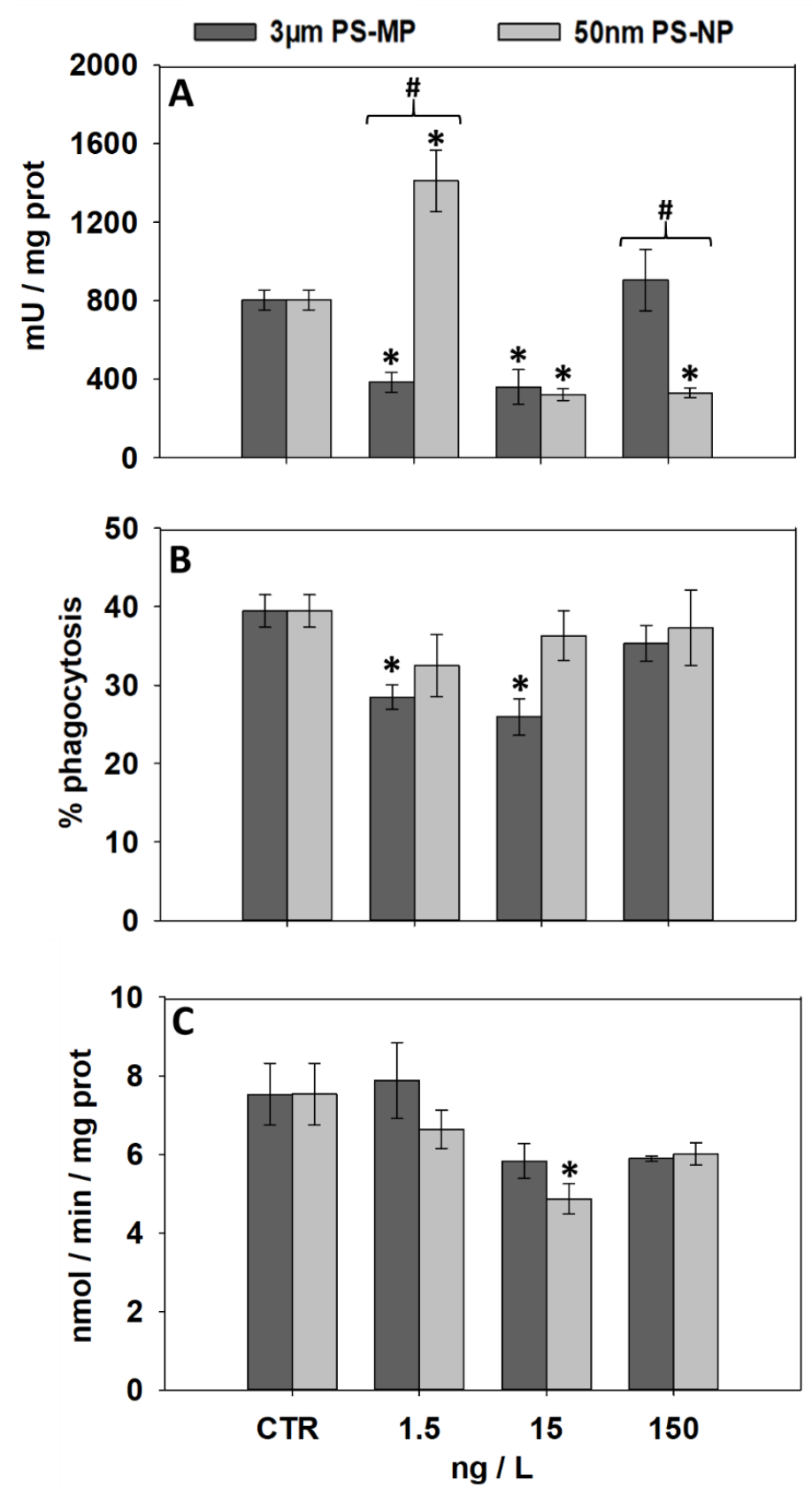

Figure 4. Immunological and neurological parameters (mean $\pm \mathrm{SEM}, \mathrm{N}=3$ ) analyzed in mussels after 21 days of exposure to PS-MP and PS-NP; (A), lysozyme activity (LSZ) in the hemolymph serum; (B), hemocytes phagocytic activity; (C), acetylcholinesterase (AChE) activity in gills. *, significant $(p<0.05)$ differences compared to control samples (CTR); \#, significant differences $(p<0.05)$ between PS-MP and PS-NP treatments.

\subsection{PCA and MES Data Integration}

The output of the PCA performed on data from PS-MP and PS-NP treatments is shown in Figure 5. The first two axes accounted for $77 \%$ of the total variance. Data from control (CTR) clustered together in the PC1 $<0 / \mathrm{PC} 2>0$ domain. Data from 1.5 and $15 \mathrm{ng} / \mathrm{L}$ PS-MP scored for PC1 > 0/PC2 < 0 . Data from $150 \mathrm{ng} / \mathrm{L}$ PS-MP and $1.5 \mathrm{ng} / \mathrm{L}$ PS-NP were scaled at PC $1<0 / \mathrm{PC} 2<0$, while those from 15 and $150 \mathrm{ng} / \mathrm{L}$ PS-MP show coordinates $>0$ for both PC1 and PC2. According to variable vectors, data from phagocytosis (PHG), 
LMS, LYS/CYT, GST, and AChE show coordinates in the PC1 $>0 / \mathrm{PC} 2>0$ domain; NL and $\mathrm{LF}$, as well as MDA and CAT clustered in the PC1 $>0 / \mathrm{PC} 2<0$ domain, while lysozyme activity (LSZ) was the only variable clustering at $\mathrm{PC} 1<0 / \mathrm{PC} 2<0$.

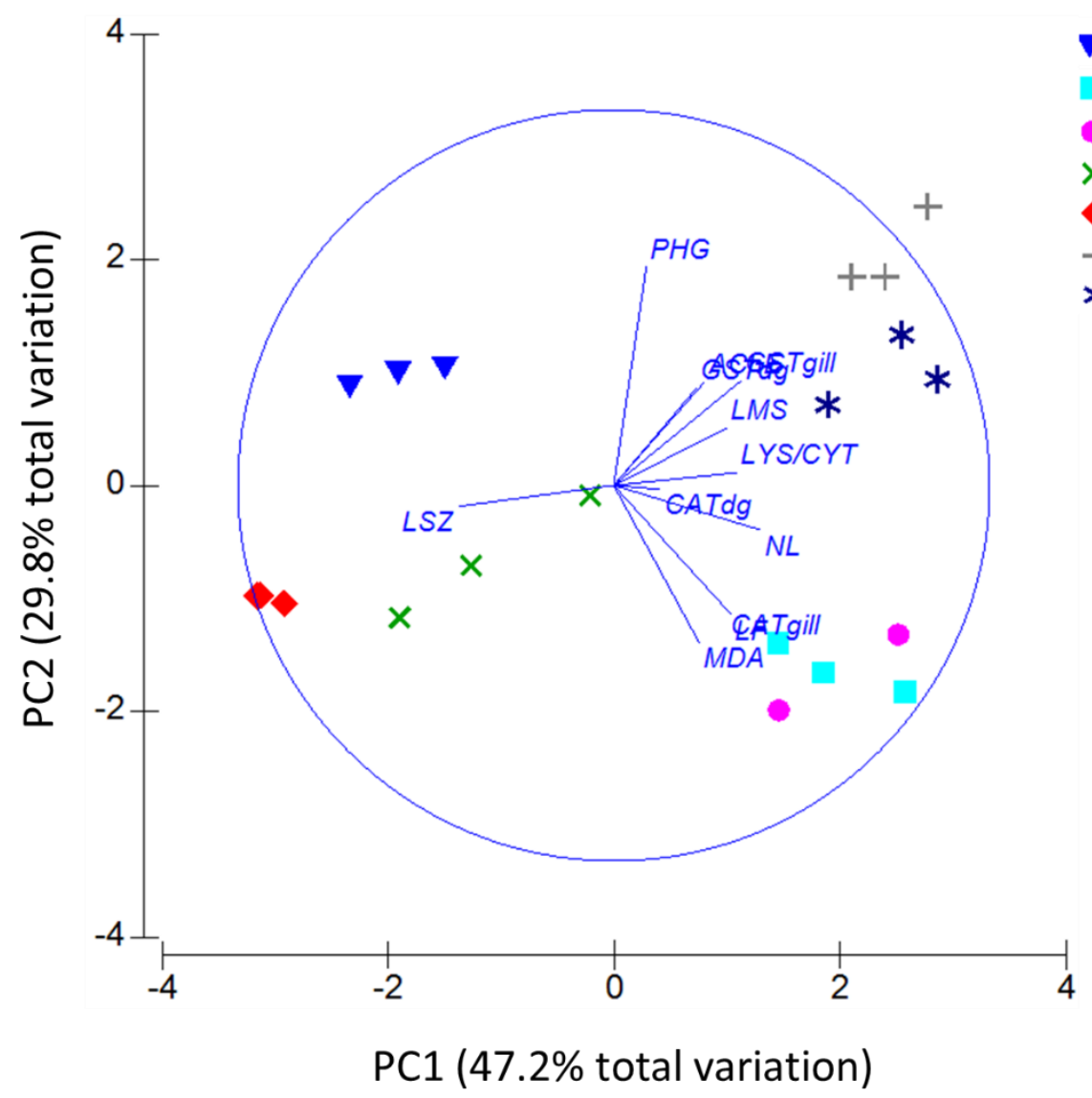

$\checkmark$ CTR

$1.5 \mathrm{ng} / \mathrm{L}$ PS-MP

$15 \mathrm{ng} / \mathrm{L}$ PS-MP

$\times 150 \mathrm{ng} / \mathrm{L}$ PS MP

$1.5 \mathrm{ng} / \mathrm{L}$ PS-NP

$+15 \mathrm{ng} / \mathrm{L}$ PS-NP

* $150 \mathrm{ng} / \mathrm{L}$ PS-NP

Figure 5. Principal component analysis (PCA). Biplot showing the PCA output including the entire set of biological data obtained in mussels exposed to increasing concentrations of PS-MP and PS-NP for 21 days.

The output of the biomarker data integration performed through the MES is shown in Table 1. The LMS was identified as the guide parameter given its known sensitivity to sublethal disturbances and its representativeness of stress-induced health status deterioration in mussels [26,37]. The system did not identify health alterations in controls and $1.5 \mathrm{ng} / \mathrm{L}$ MP treatments $(\mathrm{HSI}=\mathrm{A})$, while the onset of a low-stress level $(\mathrm{HSI}=\mathrm{B})$ was detected at 15 and $150 \mathrm{ng} / \mathrm{L}$ MP. Differently, the stress level associated with NP treatments was moderate $(\mathrm{HSI}=\mathrm{C})$ at 1.5 and $150 \mathrm{ng} / \mathrm{L}$, and high $(\mathrm{HSI}=\mathrm{D})$ at $15 \mathrm{ng} / \mathrm{L}$.

Table 1. Output of the Mussel Expert System (MES) assigning a unique health status index (HSI) to mussels exposed for 21 days to increasing concentrations of PS-MP and PS-NP.

\begin{tabular}{|c|c|c|c|c|c|c|c|}
\hline Biomarker & & 1.5 ng/L MP & 15 ng/L MP & 150 ng/L MP & 1.5 ng/L NP & 15 ng/L NP & 150 ng/L NP \\
\hline \multicolumn{8}{|l|}{ Cell } \\
\hline \multirow{2}{*}{$\mathrm{LMS}^{\mathrm{GP}}$} & $\mathbf{A F}$ & $\mathrm{NV}$ & 0.70 * & $0.59 *$ & $0.70 *$ & $0.42 *$ & 0.33 * \\
\hline & $\mathrm{AL}$ & NV & - & - & - & - & - \\
\hline \multirow{2}{*}{$\mathrm{NL}$} & AF & 1.93 * & $1.82 *$ & $1.49 *$ & $1.60 *$ & $1.79 *$ & 1.75 * \\
\hline & $\mathbf{A L}$ & + & + & + & + & + & + \\
\hline \multirow{2}{*}{$\mathrm{LF}$} & AF & 2.37 * & 2.04 * & 1.78 & 0.73 & 1.06 & 1.74 * \\
\hline & $\mathrm{AL}$ & + & NV & NV & NV & NV & + \\
\hline \multirow{2}{*}{ MDA } & AF & 2.08 & 2.38 & $2.67 *$ & 1.00 & 0.89 & 2.19 * \\
\hline & $\mathrm{AL}$ & NV & NV & ++ & NV & NV & ++ \\
\hline
\end{tabular}


Table 1. Cont.

\begin{tabular}{|c|c|c|c|c|c|c|c|}
\hline Biomarker & & $1.5 \mathrm{ng} / \mathrm{L} \mathrm{MP}$ & 15 ng/L MP & 150 ng/L MP & 1.5 ng/L NP & 15 ng/L NP & 150 ng/L NP \\
\hline \multirow{2}{*}{$\mathrm{GST}_{\mathrm{dg}}$} & $\mathbf{A F}$ & 1.15 & 0.96 & 1.13 & 1.27 & 1.30 & 1.27 \\
\hline & AL & NV & NV & NV & NV & NV & NV \\
\hline \multirow{2}{*}{$\mathrm{GST}_{\mathrm{g}}$} & $\mathbf{A F}$ & 1.18 & 1.04 & 1.13 & 0.94 & 1.35 * & 1.40 * \\
\hline & AL & NV & NV & NV & NV & + & + \\
\hline \multirow{2}{*}{$\mathrm{CAT}_{\mathrm{dg}}$} & $\mathbf{A F}$ & 0.93 & 1.06 & 0.71 & 1.17 & 0.61 & 1.25 \\
\hline & AL & NV & NV & NV & NV & NV & NV \\
\hline \multirow{2}{*}{$\mathrm{CAT}_{\mathrm{g}}$} & $\mathbf{A F}$ & $2.19 *$ & $2.24 *$ & 1.00 & $1.86 *$ & 1.44 & 1.38 \\
\hline & AL & ++ & ++ & NV & + & NV & NV \\
\hline \multirow{2}{*}{$\mathrm{AChE}$} & AF & 1.05 & 0.77 & 0.78 & 0.88 & 0.65 * & 0.80 \\
\hline & AL & NV & NV & NV & NV & - & NV \\
\hline \multirow{2}{*}{ Lysozyme } & $\mathbf{A F}$ & 0.48 * & 0.45 * & 1.13 & 1.75 * & 0.40 & 0.41 \\
\hline & AL & NV & NV & NV & + & NV & NV \\
\hline \multirow{2}{*}{ Phagocythosis } & AF & 0.72 * & $0.66^{*}$ & 0.90 & 0.82 & 0.92 & 0.95 \\
\hline & AL & NV & NV & NV & NV & NV & NV \\
\hline \multicolumn{8}{|l|}{ Tissue } \\
\hline \multirow{2}{*}{ LYS/CYT } & AF & 1.11 & 1.18 & 1.31 & 1.30 * & 1.27 * & 1.16 \\
\hline & AL & NV & NV & NV & + & + & NV \\
\hline \multicolumn{8}{|l|}{ Organism } \\
\hline \multirow{2}{*}{ Survival } & $\mathbf{A F}$ & 1.00 & 1.00 & 1.00 & 1.00 & 1.00 & 1.00 \\
\hline & AL & NV & NV & NV & NV & NV & NV \\
\hline HSI & & A (Healthy) & B (Low stress) & B (Low stress) & $\begin{array}{c}\text { C (Moderate } \\
\text { stress) }\end{array}$ & $\begin{array}{l}\text { D (High } \\
\text { stress) }\end{array}$ & $\begin{array}{c}\text { C (Moderate } \\
\text { stress) }\end{array}$ \\
\hline
\end{tabular}

LMS-lysosomal membrane stability; NL—neutral lipid content; LF-lipofuscin content; MDA-malondialdehyde content; GST ${ }_{\mathrm{dg}}$ glutathione S-transferase activity analyzed in digestive gland; GST $_{\mathrm{g}}$ - glutathione S-transferase activity analyzed in gills; $\mathrm{CAT}_{\mathrm{dg}}$ catalase activity analyzed in digestive gland; $\mathrm{CAT}_{\mathrm{g}}$ - catalase activity analyzed in gills; AChE-acetylcholinesterase activity; LYS/CYT lysosome/cytoplasm volume ratio; GP-guide parameter; HSI-health status index; AF-alteration factor; AL-alteration level. AL thresholds for increasing/bell-shaped biomarkers: "NV" (no variation) = AF $<1.2 ;$ " + " = AF $>1.2 ;$ " ++ " $=\mathrm{AF}>2.00$; AF thresholds for decreasing

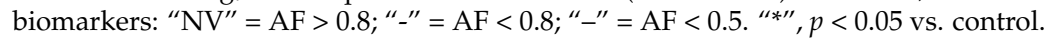

\section{Discussion}

The fragmentation of MP to nano-scaled particles is acknowledged as a real environmental risk, notably concerning the higher potential for $<100 \mathrm{~nm}$ plastics to cross biological membranes [4]. In this respect, the present study aimed at comparatively assessing the chronic effects of polystyrene micro and nanoparticles on the cellular and physiological fitness of the Mediterranean mussel M. galloprovincialis.

The LMS is the most sensitive biomarker of general stress in mussels, and its reduction is recognized as prognostic of alterations to higher functions, such as growth and/or reproduction $[38,39]$. In this study, an overall LMS reduction was observed in M. galloprovincialis hemocytes after 21 days of exposure to both PS-MP and PS-NP, corroborating recent evidence obtained in bivalves exposed to plastic particles of diverse types and sizes [40]. In addition, data reveal an overall higher lysosomal destabilization triggered by PS-NP compared to PS-MP treatments. Previous reports suggest that these differences might be attributed to a substantially higher lysosomotropic behavior of nano-sized plastics. In fact, mechanistic links were highlighted between LMS alterations in oysters and the intra-lysosomal migration of nanomaterials, including gold, silver, and fullerene nanoparticles (3 to $25 \mathrm{~nm}$ ) [41]. More recent findings obtained in mammal fibroblasts further indicate that 50-nm PS-NP readily migrates into lysosomes, leading to dysfunctions spanning from the blockage of degradative pathways to a severe increase of the lysosomal membrane permeabilization [42].

The bivalve digestive gland is responsible for key metabolic functions, including food intracellular uptake/digestion and reserve substances storage, among others [43]. The lysosomal swelling in cells surrounding the tubular epithelium of the mussel digestive gland is a known physio-pathological condition induced by stress factors of chemical and physical nature [30,44]. Between PS-NP and PS-MP, only the former induced an LYS/CYT increase in the mussel digestive cells. This may reflect the onset of an NP-mediated stimu- 
lation of intra-lysosomal migration pathways, which ultimately led to increased lysosomal volume by altering autophagic processes and enhancing cell vacuole aggregation. In line with this hypothesis, Gaspar et al. [45] recently observed that 50-nm PS particles exhibit a much greater propensity for endo-lysosomal accumulation in oyster (Crassostrea virginica) hepatopancreas cells compared to 3- $\mu \mathrm{m}$ PS-MP, indicating the potential for a higher bioreactivity and interaction with the lysosome integrity and functions. NL content measured in the mussel digestive gland showed a significant up-regulation after exposure to both PS particle sizes. These data contrast with the NL unmodified levels observed by Avio et al. [46] following a shorter (7-day) exposure of mussels to PS and polyethylene MP of different sizes. In bivalves, the NL intra-lysosomal accumulation is a known signal of lipidosis associated with either an increased cytosolic lipid content or a decreased fatty acid metabolism [26,47]. The results suggest that the prolonged uptake of "non-nutritious" PS particles may lead to the indirect depletion of energy reservoirs involved in lipid processing pathways, a physio-pathological condition already reported in the liver of mammalian models exposed to PS microparticles [48].

Morphological and functional alterations of the mussel lysosomal compartment are frequently associated with pro-oxidant conditions, which might give rise to the peroxidation of the lipid bilayer composing cell membranes [30,33]. MDA and LF are intermediate and final products of lipid peroxidation, respectively, and their determination in the mussel digestive gland has extensively been validated to ascertain the evolution of ROS-mediated effects of micro/nanoparticles of diverse nature [46,49-51]. The 21-d exposure to PS-MP and PS-NP resulted in the up-regulation of MDA and LF content in the mussel digestive gland, indicating that lipid peroxidation phenomena might be induced by PS particles irrespective of their size. However, though MDA followed a relatively similar trend of activation at increasing concentrations of both PS particle sizes, LF displayed higher sensitivity at low PS-MP when compared to PS-NP. LF are the result of the lipid peroxidation residues binding with intracellular food degradation by-products, including oxidatively modified proteins, carbohydrates, and/or metals, and are thus thought to reliably reflect the organisms' nutritional status [52]. As a conservative strategy, marine mussels tend to down-regulate their filtration rate when exposed to increasing concentrations of planktonsized plastic items [53]. In this respect, the decreasing LF profile at increasing PS-MP could reflect a progressive reduction of the feeding/filtration rate at increasing PS-NP dosages, which would also explain the partial discrepancy with respect to MDA.

To better evaluate the extent of oxidative stress conditions triggered by PS-MP and PS-NP, the MDA and LF measurements were associated with the analysis of the specific activity of the antioxidant/detoxification enzymes CAT and GST. Despite an up-regulation of lipid peroxidation products, CAT and GST activities were not affected in the mussel digestive gland, suggesting that pro-oxidative damages were not such to induce major perturbations and antioxidant responses in this tissue. On the other hand, both enzymes seem to show a mutually interconnected trend in gills with respect to PS-NP treatments: while a CAT up-regulation was observed at $1.5 \mathrm{ng} / \mathrm{L}$, higher dosages corresponded to a progressively lower CAT activity and a significant GST up-regulation. Such a complementary modulation may provide a reliable clue on the mechanisms underlying the ROS-scavenging network activated in mussel gills in response to plastic nanoparticles, corroborating doseresponse pathways observed in response to increasing levels of diverse physico-chemical stressors [54]. PS-MP did not induce GST changes in mussel gills, while CAT showed a typical bell-shaped trend, indicating that the antioxidant response to PS items could remarkably change depending on either the particle size or the analyzed tissue.

One of the most concerning risks of the MP and NP uptake is related to their potential to interfere with innate immune responses, altering the organisms' defense mechanisms toward microbiological stressors [55-58]. In bivalves, the hemolymph is the major biological compartment involved in the immune response and recent evidence indicates clear concentration-dependent trends of migration and accumulation of PS particles in this tissue, even after short-term (4-day) exposures [17]. Within the hemolymph, the first line of defense 
toward host interactions is represented by the extracellular and intracellular degradation mechanisms governed by the hemocytes, including the lysozyme extracellular release and the phagocytosis of non-self material $[59,60]$. The exposure to PS-MP and PS-NP had an overall inhibiting effect on the lysozyme activity in the mussel hemolymph serum, except for $1.5 \mathrm{ng} / \mathrm{L}$ PS-NP, which led to a sharp lysozyme up-regulation. A lysozyme inhibition is a clear signal of alteration of the hemocyte bactericidal competence, which might expose organisms to higher risks for host colonization or infection [61]. Lysozyme alterations have frequently been reported in bivalves following exposure to many classes of chemical and physical stressors (reviewed by Giròn-Perez, 2010). In a previous in vitro investigation, Canesi et al. [59] showed that the lysozyme activity of mussel hemolymph serum is activated within 30 min from exposure to amino-modified polystyrene NP (PS-NH2) but drops to basal levels thereafter. Similarly, an in vivo investigation recently performed by Auguste et al. [24] showed that repeated mussel exposures for $24 \mathrm{~h}$ to PS-NH2 resulted in a bell-shaped lysozyme activity in hemolymphs. This suggests that under a PS-NP gradient and following long-term exposures, the lysozyme synthesis and activity might show an initial "host-driven" enhancement followed by a sharp down-regulation, likely resulting from increased catabolic activity in response to the external insult, as reported for other classes of enzymes in mussels [26].

The results showed a general inhibition of the hemocyte phagocytic activity in mussels exposed to PS-MP. A decreased phagocytosis is associated with an impaired fitness of the cell-mediated host responses. In line with our findings, Tang et al. [62] recently reported a decreased phagocytic activity in hemocytes of blood clams (Tegillarca granosa) exposed to 0.5-30 $\mu \mathrm{m}$ PS-MP. No down-regulation was however observed in Mytilus spp. following sub-chronic ( $3 \mathrm{~h}-7 \mathrm{~d}$ ) exposures to $<100-\mu \mathrm{m}$ PS particles $[46,63,64]$, suggesting that MPrelated alterations of immunological processes are functionally expressed in mussels only after relatively long periods of exposure. The direct MP phagocytosis has been documented in mussel hemocytes [63]. Although the adverse effects (directly or indirectly) of MP phagocytosis on the endo-lysosomal system still need to be fully elucidated, it cannot be ruled out that this phenomenon may limit the overall cell phagocytic capacity, thus explaining the decreased zymosan particle phagocytosis observed herein.

Interestingly, the exposure to increasing PS-MP concentrations produced similar Ushaped effects on lysozyme and phagocytic activity, while notably the former showed an opposite trend in response to PS-NP, as previously described. Hormetic responses to plastic particles have been reported in many aquatic species and suggest the modulation of adaptation strategies in the presence of increasing stress stimulus [65-68]. Although the influence of particle size in shaping these processes remains to be established, the results suggest that MP and NP produce distinct host-driven responses in mussel hemocytes, which in turn may activate different compensatory mechanisms at increasing concentrations.

This study also provides evidence of potential neurotoxicity in mussels exposed to PS$\mathrm{NP}$, ascribable to a reduction of the AChE specific activity. AChE is involved in the nervous stimulus release and its selective inhibition represents the mechanism of action of many organochlorine pesticides [69]. In aquatic species, the AChE down-regulation is a known consequence of toxicant exposure and may result in alterations of synaptic pathways governing muscle contraction or heart beating [34,70]. Further studies demonstrated that plastic particles of different size affect cholinergic pathways in bivalve mollusks [46,71] and evidence also exist for teleost fish [72,73]. In this respect, the results highlight the need for a better understanding of the mechanisms underlying the anti-cholinesterasic effects of plastic nanoparticles in order to estimate the possible consequences of plastic fragmentation on the neurological fitness of the exposed biota.

The PCA highlighted the spatial clusterization of data from control with respect to treated mussels; however, treatments differing for concentration and/or size of proffered PS particles tended to cluster together based on the measured biological endpoints. This can be observed for 1.5 and $15 \mathrm{ng} / \mathrm{L}$ PS-MP, which clustered together depending on oxidative stress parameters LF, MDA, and CAT (in gills). Treatments of 15 and 150 ng/L PS-NP 
also showed similar clustering based on GST and LMS data, while scores for $150 \mathrm{ng} / \mathrm{L}$ PS-MP and $1.5 \mathrm{ng} / \mathrm{L}$ PS-NP seem to be mainly attributed to the variations induced by these treatments on the lysozyme activity (LSZ).

The integration of biomarker data in the MES assigned an absent to low stress level $(\mathrm{HSI}=\mathrm{A}-\mathrm{B})$ to alterations observed in PS-MP exposed mussels, while moderate to high stress (HSI $=\mathrm{C}-\mathrm{D})$ was assigned to PS-NP treatments. Overall, this highlights that the 21-day exposure to 1.5, 15, and $150 \mathrm{ng} / \mathrm{L}$ PS-NP had an overall higher impact on the mussel physiology compared to PS-MP, indicating that the environmental fragmentation of MP to nano-sized particles may adversely affect the fitness of exposed organisms. As suggested by the calculated AFs and ALs, differences in HSI levels apparently reflect a higher impact of PS-NP on selected general stress biomarkers (notably LMS, chosen as the guide parameter, and LYS/CYT), confirming the role of lysosomal parameters in modulating the fitness of mussels along an increasing stress gradient. Interestingly, the overall stress level exposure decreased from high to moderate at increasing concentrations of PS-NP (i.e., from 15 to $150 \mathrm{ng} / \mathrm{L}$ ). This apparently reflects the bell-shaped modulation of oxidative stress (i.e., LF) lysosomal and immunological parameters, which might result from the mussel's ability to moderate its filtration rate in the presence of an increasing external stressor stimulus [53].

\section{Conclusions}

This study demonstrated that the 21-day exposure to PS-MP and PS-NP can affect the fitness of the Mediterranean mussel $M$. galloprovincialis by selectively modulating biochemical, cellular, and physiological processes. PS-NP had an overall greater effect than PS-MP on lysosomal parameters, as LMS and LYS/CYT, suggesting a higher potential for nano-sized plastics to elicit lysosomal dysfunctions associated with the onset of a general stress syndrome. Both particle types induced lipid peroxidation and a bell-shaped activation of the antioxidant enzyme CAT; however, PS-NP induced greater effects on GST and lysozyme activities, while only PS-MP inhibited the hemocyte phagocytosis, suggesting that the PS particle size play a major role in modulating immunological and detoxification pathways in mussels. In addition, only PS-NP affected the AChE activity, accenting the potential for plastic nano-fragments to impair neurological functions in the long term.

Overall, the results highlight that the fragmentation of PS microparticles to nanoscaled fragments might enhance their ability to interfere with lysosomal, neurological, and immunological functions, leading to an exacerbation of the impacts induced on the mussel health conditions. Further efforts are necessary to ascertain the interaction of plastics of different sizes at the cell level, notably for what concerns the ability of nanoplastics to cross biological membranes and interact with key processes involved in cell homeostasis and functions in mussels. The findings obtained herein may support risk assessment models for marine plastic pollution and provide valuable clues for future investigations aimed at ascertaining the cumulative risks associated with the sorption (or leaching) of chemical pollutants/additives on the mechanisms modulating the physiological fitness of marine organisms.

Supplementary Materials: The following are available online at https:/ / www.mdpi.com/2079-499 1/11/3/649/s1, Section S1: Selected polystyrene micro- and nano-sized particles, Table S1: Tissue treatment preliminary to the analysis of enzymatic/biochemical biomarkers.

Author Contributions: Conceptualization, E.F. and M.C.; methodology, M.C., and P.V.; software, M.C. and P.V.; validation, E.F. and M.C.; formal analysis, M.C.; investigation, M.C.; resources, E.F. and P.V.; data curation, M.C.; writing — original draft preparation, M.C.; writing—review and editing, E.F.; visualization, M.C.; supervision, E.F.; project administration, E.F.; funding acquisition, E.F. All authors have read and agreed to the published version of the manuscript.

Funding: This work has been conducted as part of the European project 'PLASTOX' (Direct and indirect ecotoxicological impacts of microplastics on marine organisms) (grant agreement Nr. 696324), under the framework of the Joint Programming Initiative-Healthy and Productive Seas and Oceans 
(JPI Oceans) and has been directly funded by the MIUR-Italian Ministry of Education, University and Research (Prot. N. 6962 31/03/2015).

Institutional Review Board Statement: No specific authorization is required for the use of Mytilus galloprovincialis in experimental applications according to the EC Directive 2010/63/EU.

Informed Consent Statement: Not Applicable.

Conflicts of Interest: The authors declare that there are no conflicting interest regarding the publication of this work.

\section{References}

1. PlasticsEurope. Plastics Europe-The Facts 2020: An Analysis of European Plastics Production, Demand and Waste Data; PlasticsEurope: Brussels, Belgium, 2020; pp. 1-64.

2. United Nations Environment Programme. Marine Plastic Debris and Microplastics—Global Lessons and Research to Inspire Action and Guide Policy Change; United Nations Environment Programme: Nairobi, Kenya, 2016; pp. 1-252, ISBN 978-92-807-3580-6.

3. Pinto Da Costa, J.; Rocha-santos, T.; Duarte, A.C. The Environmental Impacts of Plastics and Micro-Plastics Use, Waste and Pollution: EU and National Measures—Requested by the Peti Committee; European Union-PE 658.279; European Union: Brussels, Belgium, 2020; pp. 1-72.

4. Galloway, T.S.; Cole, M.; Lewis, C. Interactions of microplastic debris throughout the marine ecosystem. Nat. Ecol. Evol. 2017, 1, 0116. [CrossRef] [PubMed]

5. Gunaalan, K.; Fabbri, E.; Capolupo, M. The hidden threat of plastic leachates: A critical review on their impacts on aquatic organisms. Water Res. 2020, 184, 116170. [CrossRef] [PubMed]

6. GESAMP The Joint Group of Experts on Scientific Aspects of Marine Protection. Sources, Fate and Effects of Microplastics in the Marine Environment: Part Two of a Global Assessment; Kershaw, P.J., Rochman, C.M., Eds.; International Maritime Organization: London, UK, 2016; p. 220.

7. Guzzetti, E.; Sureda, A.; Tejada, S.; Faggio, C. Microplastic in marine organism: Environmental and toxicological effects. Environ. Toxicol. Pharmacol. 2018, 64, 164-171. [CrossRef] [PubMed]

8. Setälä, O.; Lehtiniemi, M.; Coppock, R.; Cole, M. Microplastics in Marine Food Webs. In Microplastic Contamination in Aquatic Environments-An Emerging Matter of Environmental Urgency; Zeng, E., Ed.; Elsevier: Amsterdam, The Netherlands, 2018; pp. 339-363. [CrossRef]

9. Foekema, E.M.; De Gruijter, C.; Mergia, M.T.; van Franeker, J.A.; Murk, A.J.; Koelmans, A.A. Plastic in North Sea fish. Environ. Sci. Technol. 2013, 47, 8818-8824. [CrossRef]

10. Nelms, S.E.; Duncan, E.M.; Broderick, A.C.; Galloway, T.S.; Godfrey, M.H.; Hamann, M.; Lindeque, P.K.; Godley, B.J. Plastic and marine turtles: A review and call for research. ICES J. Mar. Sci. 2016, 73, 165-181. [CrossRef]

11. Lu, Y.; Zhang, Y.; Deng, Y.; Jiang, W.; Zhao, Y.; Geng, J.; Ding, L.; Ren, H. Uptake and accumulation of polystyrene microplastics in zebrafish (Danio rerio) and toxic effects in liver. Environ. Sci. Technol. 2016, 50, 4054-4060. [CrossRef]

12. Rochman, C.M.; Hoh, E.; Kurobe, T.; Teh, S.J. Ingested plastic transfers hazardous chemicals to fish and induces hepatic stress. Sci. Rep. 2013, 3, 3263. [CrossRef]

13. Cole, M.; Lindeque, P.; Fileman, E.; Halsband, C.; Galloway, T.S. The Impact of Polystyrene Microplastics on Feeding, Function and Fecundity in the Marine Copepod Calanus helgolandicus. Environ. Sci. Technol. 2015, 49, 1130-1137. [CrossRef]

14. Piarulli, S.; Vanhove, B.; Comandini, P.; Scapinello, S.; Moens, T.; Vrielinck, H.; Sciutto, G.; Prati, S.; Mazzeo, R.; Booth, A.M.; et al. Do different habits affect microplastics contents in organisms? A trait-based analysis on salt marsh species. Mar. Pollut. Bull. 2020, 153, 110983. [CrossRef]

15. Wright, S.L.; Rowe, D.; Thompson, R.C.; Galloway, T.S. Microplastic ingestion decreases energy reserves in marine worms. Curr. Biol. 2013, 23, R1031-R1033. [CrossRef]

16. Capolupo, M.; Franzellitti, S.; Valbonesi, P.; Lanzas, C.S.; Fabbri, E. Uptake and transcriptional effects of polystyrene microplastics in larval stages of the Mediterranean mussel Mytilus galloprovincialis. Environ. Pollut. 2018, 241, 1038-1047. [CrossRef]

17. Franzellitti, S.; Capolupo, M.; Wathsala, R.H.G.R.; Valbonesi, P.; Fabbri, E. The Multixenobiotic resistance system as a possible protective response triggered by microplastic ingestion in Mediterranean mussels (Mytilus galloprovincialis): Larvae and adult stages. Comp. Biochem. Physiol. Part C 2019, 219, 50-58. [CrossRef]

18. Murano, C.; Agnisola, C.; Caramiello, D.; Castellano, I.; Casotti, R.; Corsi, I.; Palumbo, A. How sea urchins face microplastics: Uptake, tissue distribution and immune system response. Environ. Pollut. 2020, 264, 114685. [CrossRef]

19. Stapleton, P.A. Toxicological considerations of nano-sized plastics. AIMS Environ. Sci. 2019, 6, 367-378. [CrossRef] [PubMed]

20. Hollóczki, O.; Gehrke, S. Can Nanoplastics Alter Cell Membranes? ChemPhysChem 2020, 21, 9-12. [CrossRef]

21. Sun, X.; Chen, B.; Li, Q.; Liu, N.; Xia, B.; Zhu, L.; Qu, K. Science of the Total Environment Toxicities of polystyrene nano- and microplastics toward marine bacterium Halomonas alkaliphila. Sci. Total Environ. 2018, 642, 1378-1385. [CrossRef] [PubMed]

22. Bergami, E.; Pugnalini, S.; Vannuccini, M.L.; Manfra, L.; Faleri, C.; Savorelli, F.; Dawson, K.A.; Corsi, I. Long-term toxicity of surface-charged polystyrene nanoplastics to marine planktonic species Dunaliella tertiolecta and Artemia franciscana. Aquat. Toxicol. 2017, 189, 159-169. [CrossRef] 
23. Sendra, M.; Carrasco-Braganza, M.I.; Yeste, P.M.; Vila, M.; Blasco, J. Immunotoxicity of polystyrene nanoplastics in different hemocyte subpopulations of Mytilus galloprovincialis. Sci. Rep. 2020, 10, 8637. [CrossRef] [PubMed]

24. Auguste, M.; Lasa, A.; Balbi, T.; Pallavicini, A.; Vezzulli, L.; Canesi, L. Impact of nanoplastics on hemolymph immune parameters and microbiota composition in Mytilus galloprovincialis. Mar. Environ. Res. 2020, 159, 105017. [CrossRef]

25. Brandts, I.; Teles, M.; Gonçalves, A.P.; Barreto, A.; Franco-martinez, L.; Tvarijonaviciute, A. Science of the Total Environment Effects of nanoplastics on Mytilus galloprovincialis after individual and combined exposure with carbamazepine. Sci. Total Environ. 2018, 643, 775-784. [CrossRef] [PubMed]

26. Viarengo, A.; Lowe, D.; Bolognesi, C.; Fabbri, E.; Koehler, A. The use of biomarkers in biomonitoring: A 2-tier approach assessing the level of pollutant-induced stress syndrome in sentinel organisms. Comp. Biochem. Physiol. C Toxicol. Pharmacol. 2007, 146, 281-300. [CrossRef] [PubMed]

27. Lowry, O.H.; Rosebrough, N.J.; Farr, A.; Randall, R.J. Protein measurement with the Folin phenol reagent. J. Biol. Chem. 1951, 193, 265-275. [CrossRef]

28. Martínez-Gómez, C.; Bignell, J.; Lowe, D. Lysosomal Membrane Stability in Mussels; ICES Techniques in Marine Environmental Sciences; International Council for the Exploration of the Sea (ICES): Copenhagen, Denmark, 2015; pp. 1-41, ISBN 9788774821663.

29. United Nations Environment Programme/RAMOGE. Manual on the Biomarkers Recommended for the Med Pol Biomonitoring Programme; United Nations Environment Programme: Athens, Greece, 1999; ISBN 928071788X.

30. Capolupo, M.; Franzellitti, S.; Kiwan, A.; Valbonesi, P.; Dinelli, E.; Pignotti, E.; Birke, M.; Fabbri, E. A comprehensive evaluation of the environmental quality of a coastal lagoon (Ravenna, Italy): Integrating chemical and physiological analyses in mussels as a biomonitoring strategy. Sci. Total Environ. 2017, 598, 146-159. [CrossRef] [PubMed]

31. Martín-Díaz, M.L.; Gagné, F.; Blaise, C. The use of biochemical responses to assess ecotoxicological effects of Pharmaceutical and Personal Care Products (PPCPs) after injection in the mussel Elliptio complanata. Environ. Toxicol. Pharmacol. 2009, 28, 237-242. [CrossRef]

32. Franzellitti, S.; Buratti, S.; Capolupo, M.; Du, B.; Haddad, S.P.; Chambliss, C.K.; Brooks, B.W.; Fabbri, E. An exploratory investigation of various modes of action and potential adverse outcomes of fluoxetine in marine mussels. Aquat. Toxicol. 2014, 151, 14-26. [CrossRef] [PubMed]

33. Capolupo, M.; Valbonesi, P.; Kiwan, A.; Buratti, S.; Franzellitti, S.; Fabbri, E. Use of an integrated biomarker-based strategy to evaluate physiological stress responses induced by environmental concentrations of caffeine in the Mediterranean mussel Mytilus galloprovincialis. Sci. Total Environ. 2016, 563-564, 538-548. [CrossRef]

34. Valbonesi, P.; Sartor, G.; Fabbri, E. Characterization of cholinesterase activity in three bivalves inhabiting the North Adriatic sea and their possible use as sentinel organisms for biosurveillance programmes. Sci. Total Environ. 2003, 312, 79-88. [CrossRef]

35. Chu, F.L.E.; La Peyre, J.F. Effect of environmental factors and parasitism on hemolymph lysozyme and protein of American oysters (Crassostrea virginica). J. Invertebr. Pathol. 1989, 54, 224-232. [CrossRef]

36. Canesi, L.; Betti, M.; Lorusso, L.C.; Ciacci, C.; Gallo, G. In vivo effects of Bisphenol A in Mytilus hemocytes: Modulation of kinase-mediated signalling pathways. Aquat. Toxicol. 2005, 71, 73-84. [CrossRef] [PubMed]

37. Dagnino, A.; Allen, J.I.; Moore, M.N.; Broeg, K.; Canesi, L.; Viarengo, A. Development of an expert system for the integration of biomarker responses in mussels into an animal health index. Biomarkers 2007, 12, 155-172. [CrossRef]

38. Martínez-Gómez, C.; Robinson, C.D.; Burgeot, T.; Gubbins, M.; Halldorsson, H.P.; Albentosa, M.; Bignell, J.P.; Hylland, K.; Vethaak, A.D. Biomarkers of general stress in mussels as common indicators for marine biomonitoring programmes in Europe: The ICON experience. Mar. Environ. Res. 2017, 124, 70-80. [CrossRef] [PubMed]

39. Moore, M.N.; Allen, J.I.; McVeigh, A.; Shaw, J. Lysosomal and autophagic reactions as predictive indicators of environmental impact in aquatic animals. Autophagy 2006, 2, 217-220. [CrossRef] [PubMed]

40. Franzellitti, S.; Canesi, L.; Auguste, M.; Wathsala, R.H.G.R.; Fabbri, E. Microplastic exposure and effects in aquatic organisms: A physiological perspective. Environ. Toxicol. Pharmacol. 2019, 68, 37-51. [CrossRef]

41. Ringwood, A.H.; Levi-Polyachenko, N.; Carroll, D.L. Fullerene exposures with oysters: Embryonic, adult, and cellular responses. Environ. Sci. Technol. 2009, 43, 7136-7141. [CrossRef]

42. Wang, F.; Salvati, A.; Boya, P. Lysosome-dependent cell death and deregulated autophagy induced by amine-modified polystyrene nanoparticles. Open Biol. 2018, 8, 170271. [CrossRef] [PubMed]

43. Dailianis, S. Environmental impact of anthropogenic activities: The use of mussels as a reliable tool for monitoring marine pollution. In Mussels: Anatomy, Habitat and Environmental Impact; McGevin, L.E., Ed.; Nova Science Publishers: Hauppauge, NY, USA, 2010; pp. 1-30, ISBN 9781617617638.

44. Orbea, A.; Garmendia, L.; Marigómez, I.; Cajaraville, M.P. Effects of the "Prestige" oil spill on cellular biomarkers in intertidal mussels: Results of the first year of studies. Mar. Ecol. Prog. Ser. 2006, 306, 177-189. [CrossRef]

45. Gaspar, T.R.; Chi, R.J.; Parrow, M.W.; Ringwood, A.H. Cellular bioreactivity of micro- and nano-plastic particles in oysters. Front. Mar. Sci. 2018, 5, 1-8. [CrossRef]

46. Avio, C.G.; Gorbi, S.; Milan, M.; Benedetti, M.; Fattorini, D.; Pauletto, M.; Bargelloni, L.; Regoli, F. Pollutants bioavailability and toxicological risk from microplastics to marine mussels. Environ. Pollut. 2015, 198, 211-222. [CrossRef]

47. Moore, M. Cytochemical responses of the lysosomal system and NADPH-ferrihemoprotein reductase in molluscan digestive cells to environmental and experimental exposure to xenobiotics. Mar. Ecol. Prog. Ser. 1988, 46, 81-89. [CrossRef] 
48. Lu, L.; Wan, Z.; Luo, T.; Fu, Z.; Jin, Y. Polystyrene microplastics induce gut microbiota dysbiosis and hepatic lipid metabolism disorder in mice. Sci. Total Environ. 2018, 631-632, 449-458. [CrossRef]

49. Auguste, M.; Balbi, T.; Montagna, M.; Fabbri, R.; Sendra, M.; Blasco, J.; Canesi, L. In vivo immunomodulatory and antioxidant properties of nanoceria $\left(\mathrm{nCeO}_{2}\right)$ in the marine mussel Mytilus galloprovincialis. Comp. Biochem. Physiol. Part C Toxicol. Pharmacol. 2019, 219, 95-102. [CrossRef]

50. Gomes, T.; Pereira, C.G.; Cardoso, C.; Pinheiro, J.P.; Cancio, I.; Bebianno, M.J. Accumulation and toxicity of copper oxide nanoparticles in the digestive gland of Mytilus galloprovincialis. Aquat. Toxicol. 2012, 118-119, 72-79. [CrossRef] [PubMed]

51. Koehler, A.; Marx, U.; Broeg, K.; Bahns, S.; Bressling, J. Effects of nanoparticles in Mytilus edulis gills and hepatopancreas-A new threat to marine life? Mar. Environ. Res. 2008, 66, 12-14. [CrossRef] [PubMed]

52. Moore, M.N. Autophagy as a second level protective process in conferring resistance to environmentally-induced oxidative stress. Autophagy 2008, 4, 254-256. [CrossRef] [PubMed]

53. Woods, M.N.; Stack, M.E.; Fields, D.M.; Shaw, S.D.; Matrai, P.A. Microplastic fiber uptake, ingestion, and egestion rates in the blue mussel (Mytilus edulis). Mar. Pollut. Bull. 2018, 137, 638-645. [CrossRef]

54. Regoli, F.; Giuliani, M.E. Oxidative pathways of chemical toxicity and oxidative stress biomarkers in marine organisms. Mar. Environ. Res. 2014, 93, 106-117. [CrossRef]

55. Bergami, E.; Krupinski Emerenciano, A.; González-Aravena, M.; Cárdenas, C.A.; Hernández, P.; Silva, J.R.M.C.; Corsi, I. Polystyrene nanoparticles affect the innate immune system of the Antarctic sea urchin Sterechinus neumayeri. Polar Biol. 2019, 42, 743-757. [CrossRef]

56. Greven, A.C.; Merk, T.; Karagöz, F.; Mohr, K.; Klapper, M.; Jovanović, B.; Palić, D. Polycarbonate and polystyrene nanoplastic particles act as stressors to the innate immune system of fathead minnow (Pimephales promelas). Environ. Toxicol. Chem. 2016, 35, 3093-3100. [CrossRef]

57. Hamed, M.; Soliman, H.A.M.; Osman, A.G.M.; Sayed, A.E.D.H. Assessment the effect of exposure to microplastics in Nile Tilapia (Oreochromis niloticus) early juvenile: I. blood biomarkers. Chemosphere 2019, 228, 345-350. [CrossRef]

58. Yong, C.Q.Y.; Valiyaveetill, S.; Tang, B.L. Toxicity of microplastics and nanoplastics in Mammalian systems. Int. J. Environ. Res. Public Health 2020, 17, 1509. [CrossRef]

59. Canesi, L.; Ciacci, C.; Bergami, E.; Monopoli, M.P.; Dawson, K.A.; Papa, S.; Canonico, B.; Corsi, I. Evidence for immunomodulation and apoptotic processes induced by cationic polystyrene nanoparticles in the hemocytes of the marine bivalve Mytilus. Mar. Environ. Res. 2015, 111, 34-40. [CrossRef] [PubMed]

60. Li, H.; Parisi, M.G.; Toubiana, M.; Cammarata, M.; Roch, P. Lysozyme gene expression and hemocyte behaviour in the Mediterranean mussel, Mytilus galloprovincialis, after injection of various bacteria or temperature stresses. Fish Shellfish Immunol. 2008, 25, 143-152. [CrossRef] [PubMed]

61. Callewaert, L.; Van Herreweghe, J.M.; Vanderkelen, L.; Leysen, S.; Voet, A.; Michiels, C.W. Guards of the great wall: Bacterial lysozyme inhibitors. Trends Microbiol. 2012, 20, 501-510. [CrossRef] [PubMed]

62. Tang, Y.; Rong, J.; Guan, X.; Zha, S.; Shi, W.; Han, Y.; Du, X.; Wu, F.; Huang, W.; Liu, G. Immunotoxicity of microplastics and two persistent organic pollutants alone or in combination to a bivalve species. Environ. Pollut. 2020, 258, 113845. [CrossRef] [PubMed]

63. Browne, M.A.; Dissanayake, A.; Galloway, T.S.; Lowe, D.M.; Thompson, R.C. Ingested Microscopic Plastic Translocates to the Circulatory System of the Mussel, Mytilus edulis (L.). Environ. Sci. Technol. 2008, 42, 5026-5031. [CrossRef] [PubMed]

64. Paul-Pont, I.; Lacroix, C.; González Fernández, C.; Hégaret, H.; Lambert, C.; Le Goïc, N.; Frère, L.; Cassone, A.L.; Sussarellu, R.; Fabioux, C.; et al. Exposure of marine mussels Mytilus spp. to polystyrene microplastics: Toxicity and influence on fluoranthene bioaccumulation. Environ. Pollut. 2016, 216, 724-737. [CrossRef] [PubMed]

65. Alnajar, N.; Jha, A.N.; Turner, A. Impacts of microplastic fibres on the marine mussel, Mytilus galloprovinciallis. Chemosphere 2021, 262, 128290. [CrossRef] [PubMed]

66. Bringer, A.; Cachot, J.; Prunier, G.; Dubillot, E.; Clérandeau, C.; Thomas, H. Experimental ingestion of fluorescent microplastics by pacific oysters, Crassostrea gigas, and their effects on the behaviour and development at early stages. Chemosphere 2020, 254, 1-10. [CrossRef] [PubMed]

67. Silva, C.J.M.; Patrício Silva, A.L.; Campos, D.; Machado, A.L.; Pestana, J.L.T.; Gravato, C. Oxidative damage and decreased aerobic energy production due to ingestion of polyethylene microplastics by Chironomus riparius (Diptera) larvae. J. Hazard. Mater. 2021, 402, 123775. [CrossRef] [PubMed]

68. González-Soto, N.; Hatfield, J.; Katsumiti, A.; Duroudier, N.; Lacave, J.M.; Bilbao, E.; Orbea, A.; Navarro, E.; Cajaraville, M.P. Impacts of dietary exposure to different sized polystyrene microplastics alone and with sorbed benzo[a]pyrene on biomarkers and whole organism responses in mussels Mytilus galloprovincialis. Sci. Total Environ. 2019, 684, 548-566. [CrossRef] [PubMed]

69. Colovic, M.B.; Krstic, D.Z.; Lazarevic-Pasti, T.D.; Bondzic, A.M.; Vasic, V.M. Acetylcholinesterase inhibitors: Pharmacology and toxicology. Curr. Neuropharmacol. 2013, 11, 315-335. [CrossRef] [PubMed]

70. Valbonesi, P.; Brunelli, F.; Mattioli, M.; Rossi, T.; Fabbri, E. Cholinesterase activities and sensitivity to pesticides in different tissues of silver European eel, Anguilla anguilla. Comp. Biochem. Physiol. C Toxicol. Pharmacol. 2011, 154, 353-359. [CrossRef] [PubMed]

71. Ribeiro, F.; Garcia, A.R.; Pereira, B.P.; Fonseca, M.; Mestre, N.C.; Fonseca, T.G.; Ilharco, L.M.; Bebianno, M.J. Microplastics effects in Scrobicularia plana. Mar. Pollut. Bull. 2017, 122, 379-391. [CrossRef] 
72. Barboza, L.G.A.; Vieira, L.R.; Branco, V.; Figueiredo, N.; Carvalho, F.; Carvalho, C.; Guilhermino, L. Microplastics cause neurotoxicity, oxidative damage and energy-related changes and interact with the bioaccumulation of mercury in the European seabass, Dicentrarchus labrax (Linnaeus, 1758). Aquat. Toxicol. 2018, 195, 49-57. [CrossRef] [PubMed]

73. Fonte, E.; Ferreira, P.; Guilhermino, L. Temperature rise and microplastics interact with the toxicity of the antibiotic cefalexin to juveniles of the common goby (Pomatoschistus microps): Post-exposure predatory behaviour, acetylcholinesterase activity and lipid peroxidation. Aquat. Toxicol. 2016, 180, 173-185. [CrossRef] [PubMed] 